\title{
Short-term Evaluation of Survival Newborns Having Spent a Day in Neonatology at the University Clinics of Kinshasa During Severe Preeclampsia: Prospective Cohort Survey
}

\author{
Vangu Vangu Roland ${ }^{1,5}$, Rahma Rashid Tozin ${ }^{1}$, Mbungu Mwimba Roger ${ }^{1}$, \\ Nkodila Natuhoyila Aliocha ${ }^{3,}$, Longo-Mbenza Benjamin ${ }^{1,2,3}$ \\ ${ }^{1}$ Department of Gynécology and Obstétric, University of Kinshasa, Kinshasa, Congo \\ ${ }^{2}$ Department of Internal Medicine, University of Kinshasa, Kinshasa, Congo \\ ${ }^{3}$ Department of Public Health, Lomo-University Reseach, Kinshasa, Congo \\ ${ }^{4}$ Department of Sciences, University of MARIEN NGOUABI, Brazzaville, Congo \\ ${ }^{5}$ Department of Internal Medecine, University of Président Joseph KASA-VUBU, Boma, Congo
} Mbuyi Muamba Jean Marie ${ }^{2}$, Mokondjimobe Etienne ${ }^{3,4}$, Mambueni Thamba Christophe ${ }^{3}$, Vangu Ngoma Dieudonné ${ }^{3}$, Tsimba Vangu Andrien ${ }^{5}$, Makoso Nimi Blaise ${ }^{5}$, Mbungu Fuele Simon ${ }^{3}$,

Email address:

nkodilaaliocha@gmail.com (N. N. Aliocha)

* Corresponding author

To cite this article:

Vangu Vangu Roland, Rahma Rashid Tozin, Mbungu Mwimba Roger, Mbuyi Muamba Jean Marie, Mokondjimobe Etienne, Mambueni Thamba Christophe, Vangu Ngoma Dieudonné, Tsimba Vangu Andrien, Makoso Nimi Blaise, Mbungu Fuele Simon, Nkodila Natuhoyila Aliocha, Longo-Mbenza Benjamin. Short-term Evaluation of Survival Newborns Having Spent a Day in Neonatology at the University Clinics of Kinshasa During Severe Preeclampsia: Prospective Cohort Survey. European Journal of Preventive Medicine.

Vol. 8, No. 5, 2020, pp. 77-82. doi: 10.11648/j.ejpm.20200805.14

Received: August 5, 2020; Accepted: August 24, 2020; Published: October 13, 2020

\begin{abstract}
Background and aims: neonatal mortality in pregnant women with pre-eclampsia remains a concern in our environment and several factors, including those related to complications of pre-eclampsia, contribute to it in our settings where the care is inadequate. The aims of our study is to determine the frequency of transfer to describe the survival of babies born to preeclampsia mothers admitted to the Pediatric Neonatology Department of University Clinics of Kinshasa over a consecutive period of approximately 30 days. Methods: This is a prospective cohort study carried out over a period from January 1, 2006 to December 31, 2015 targeting all babies born to preeclampsia mothers followed in the neonatal service of the University Clinics of Kinshasa. Maternal, perpartal, neonatal and evolutionary characteristics (cure or death) were studied. Survival was described by the Kaplan Meier method at the 5\% significance level. Results: the recorded death rate was $26.5 \%$. Gestational age between 28-36 weeks of amenorrhea conferred a risk of death in children 3 times, compared with APGAR $<7$ at the $1 \mathrm{st}, 5$ th and 10 th which conferred a risk of 2, 3 and 3 times respectively. The overweight-obese mothers had a risk doubled of causing the death of newborns. Conclusion: The toll of neonatal mortality during preeclampsia is heavy in developing countries where newborns continue to die from often preventable causes. The reduction in neonatal morbidity and mortality requires an improvement in the system of care for newborns in our environment.
\end{abstract}

Keywords: Pre-Eclampsia, Mortality, Survival, Newborns, Neonatology, CUK

\section{Introduction}

The fourth Millennium Development Goal (MDG), aimed at reducing infant mortality by $2 / 3$ by 2022 , involves improving the quality of obstetric and neonatal care, thereby reducing neonatal mortality. Around 4 million neonatal deaths are recorded each year worldwide, and three quarters of them occur in the first week of life with the highest risk on 
the first day of life [1] and the main causes of this mortality are maternal preeclampsia, prematurity and neonatal infection [2-5]. However, to reduce neonatal mortality, it is also important to consider the factors associated with neonatal morbidity and mortality, including prevention and proper management of the mother with preeclampsia. This is how we were interested in the transfer of newborns to the neonatal care unit because it represents an indicator of morbidity that can be used to design and implement interventions to improve the health of the mother. and increase neonatal survival. The transfer of a newborn requires a rigorous organization and specific skills of medical and paramedical staff in order to anticipate and prevent as well as possible any incidents or accidents that could occur during the transfer. In France, the organization of perinatal care, on the basis of a regional network and the establishment of structures dedicated to the guidance of mothers and children in recent years, has made it possible to significantly reduce the number of children. postnatal transfers of babies born to a preeclamptic mother [6,7]. Although some local teams have looked into the causes of neonatal deaths [8], the survival of babies born to preeclampsia mothers in our context is poorly understood. Also, within the framework of the implementation of a project which to improve the survival of the newborn at the University Clinics of Kinshasa acting as a reference pole, it seemed necessary to us to describe the survival of babies born to preeclampsia mothers admitted. at the Pediatric Neonatology Department of Kinshasa University Clinics for a consecutive period of approximately 30 days.

\subsection{Patients and Methods}

This was a prospective cohort study from 2006 to December 2015. The children were recruited and followed up at the Neonatology Service of the University Clinics of Kinshasa during the period from January 2006 to December 2015. Each child was followed for 30 days depending on the year he was included in the cohort.

The study population consisted of all the children born to a preeclampsia mother recruited from the cohort and followed at the Neonatology Service of University Clinics in Kinshasa until 2015. The primary outcome was death. Children lost to follow-up have been censored.

Inclusion criteria: any child born to a preeclampsia mother transferred to Neonatology for treatment. Children admitted to neonatology whose mothers did not have preeclampsia were not included in the study. The systematic examination of the children made it possible to obtain, from an ad hoc survey sheet, the information essential for this study. Data from mothers included age, educational level, occupation, parity, pregnancy, BMI, blood pressure, history of preeclampsia, treatment and complications.

Children's data included BCF, gestational age, route of delivery, APGAR, weight, height and head circumference, and vital outcome. The BMI of the mothers was categorized into normal (BMI between 18 and $24.9 \mathrm{Kg} / \mathrm{m}^{2}$ ), overweight (BMI between 25 and $29.9 \mathrm{Kg} / \mathrm{m}^{2}$ ), obesity (BMI $\geq 30 \mathrm{Kg} / \mathrm{m}^{2}$ ).

Low birth weight was assessed in children with a birth weight of less than 2500 grams. The APGAR of less than 7 was considered bad. Survival was defined as the period starting from the 1st day of admission to neonatology of the child until the date of death for the deceased, at the last assessment for the lost to follow-up, and at the end of the study (December 31, 2015) for survivors.

\subsection{Statistical Analyzes}

The data was entered and encoded using the Epi info 3.5 software. Data analyzes were performed using SPSS version 21 software. Descriptive statistics were presented as the mean plus or minus standard deviation for the data that followed the Gaussian distribution and the Median and Interquartile Space (EIQ). For those not having a Gaussian distribution, percentages and confidence intervals $(95 \% \mathrm{CI})$ depending on the case. The Student's $t$ test made it possible to compare the means and that of chi-square made it possible to compare the proportions. Kaplan Meier's method was used to describe the survival between the date of admission in neonatal care and death (complete data) and the end of the study (censored data). Patients lost to follow-up at the end of the study $(n=4)$ were censored. The Log-rank test was used to compare survival curves. Independent predictors of mortality were sought by the Cox proportional risk method, the relative risk (RR) was calculated for each independent variable. A p value $<0.05$ was considered the threshold of statistical significance.

\subsection{Ethical Considerations}

The data was collected anonymously and confidentially. The privacy and personality of the children have been safeguarded. The three fundamental principles of ethics were respected at the time of the study: the principle of respect for the person, that of beneficence and that of justice. The protocol for this study was submitted and accepted by the DRC's National Health Ethics Committee under approval number 105 / CNES / BN / PMMF / 2018 of 3/04/2019.

\section{Results}

\section{Vital Outcome of Newborns}

During severe preeclampsia, after childbirth, 117 newborns were hospitalized in Neonatology at University Clinics in Kinshasa. Among them, $26.5 \%$ had died and $73.5 \%$ were alive (Figure 1). 


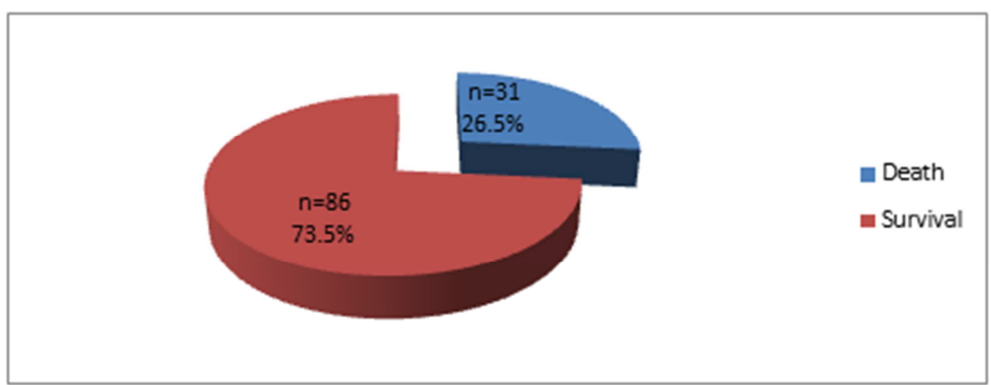

Figure 1. Distribution of children according to their vital outcome.

Table 1. Characteristics of mothers of newborns by vital outcome.

\begin{tabular}{|c|c|c|c|c|}
\hline Variables & Over all $\mathbf{n}=117$ & Survival $n=86$ & Death $n=31$ & p \\
\hline Age & $31.9 \pm 5.6$ & $31.9 \pm 6.1$ & $32.1 \pm 3.9$ & 0.868 \\
\hline $20-35$ years & $85(72.7)$ & $62(72.1)$ & $23(74.2)$ & \\
\hline$>35$ years & $32(27.4)$ & $24(27.9)$ & $8(25.8)$ & \\
\hline Level of study & & & & 0.068 \\
\hline Primary & $27(23.1)$ & $16(18.6)$ & $11(35.5)$ & \\
\hline Secondary & $48(41.0)$ & $40(46.5)$ & $8(25.8)$ & \\
\hline University & $42(35.9)$ & $30(34.9)$ & $12(38.7)$ & \\
\hline Profession & & & & 0.293 \\
\hline Unemployed & $89(76.1)$ & 67 (77.9) & $22(71.0)$ & \\
\hline Employment & $28(23.9)$ & $19(22.1)$ & $9(29.0)$ & \\
\hline Season & & & & 0.556 \\
\hline Rain & $61(52.1)$ & $45(52.3)$ & $16(51.6)$ & \\
\hline Dried & $56(47.9)$ & $41(47.7)$ & $15(48.4)$ & \\
\hline Parity & & & & 0.223 \\
\hline Primiparous & $50(42.7)$ & $36(41.9)$ & $14(45.2)$ & \\
\hline Pauciparous & $38(32.5)$ & $27(31.4)$ & $11(35.5)$ & \\
\hline Multiparous & $19(16.2)$ & $13(15.1)$ & $6(19.4)$ & \\
\hline Large multiparous & $10(8.5)$ & 10 (11.6) & $0(0.0)$ & \\
\hline Gesture & & & & 0.140 \\
\hline Primigest & $34(29.1)$ & $26(30.2)$ & $8(25.8)$ & \\
\hline Paucigest & 35 (29.9) & $28(32.6)$ & $7(22.6)$ & \\
\hline Multigest & $34(29.1)$ & $20(23.3)$ & $14(45.2)$ & \\
\hline Large multigest & $14(12.0)$ & $12(14.0)$ & $2(6.5)$ & \\
\hline \multicolumn{5}{|l|}{ Antecedents } \\
\hline Preeclampsia & $29(24.8)$ & $19(22.1)$ & $10(32.3)$ & 0.018 \\
\hline Caesarean & $17(14.5)$ & 10 (11.6) & $7(22.6)$ & 0.012 \\
\hline BMI & $28.9 \pm 4.2$ & $29.1 \pm 4.3$ & $28.4 \pm 3.6$ & 0.398 \\
\hline Normal & $23(19.7)$ & $17(19.8)$ & $6(19.4)$ & 0.212 \\
\hline Overweight & $45(38.5)$ & $28(32.6)$ & $17(54.8)$ & 0.025 \\
\hline Obesity & 49 (41.9) & $41(47.7)$ & $8(25.8)$ & 0.027 \\
\hline SBP & $176.4 \pm 20.5$ & $174.3 \pm 18.9$ & $182.3 \pm 23.8$ & 0.063 \\
\hline DBP & $115.6 \pm 12.2$ & $113.9 \pm 10.3$ & $120.3 \pm 15.6$ & 0.012 \\
\hline Proteinuria & & & & 0.443 \\
\hline++ & $9(7.7)$ & $6(7.0)$ & $3(9.7)$ & \\
\hline +++ & $108(92.3)$ & $80(93.0)$ & $28(90.3)$ & \\
\hline Edème & $99(84.6)$ & $74(86.0)$ & $25(80.6)$ & 0.327 \\
\hline \multicolumn{5}{|l|}{ Traitment } \\
\hline Therapeutic scheme 1 & $43(36.8)$ & $32(37.2)$ & $11(35.5)$ & 0.522 \\
\hline Therapeutic scheme 2 & $39(33.3)$ & $26(30.2)$ & $13(41.9)$ & 0.168 \\
\hline Therapeutic scheme 3 & $8(6.8)$ & $8(9.3)$ & $0(0.0)$ & - \\
\hline Therapeutic scheme 4 & $27(23.1)$ & $20(23.3)$ & $7(22.6)$ & 0.576 \\
\hline Complications & 37 (31.6) & $26(30.2)$ & $11(35.5)$ & 0.373 \\
\hline
\end{tabular}

Table 1 shows that children whose mothers had a history of pre-eclampsia, cesarean section and overweight were more dead $(\mathrm{p}>0.05)$.

Table 2. General characteristics of newborns according to the vital outcome.

\begin{tabular}{|c|c|c|c|c|}
\hline Variables & Over all $n=117$ & Survival $n=86$ & Death $n=31$ & p \\
\hline Fetal heart sound & & & & 0.716 \\
\hline Absent & $2(1.7)$ & $2(2.3)$ & $0(0.0)$ & \\
\hline well & $87(74.4)$ & $65(75.6)$ & $22(71.0)$ & \\
\hline
\end{tabular}




\begin{tabular}{|c|c|c|c|c|}
\hline Variables & Over all $\mathbf{n}=117$ & Survival $n=86$ & Death $n=31$ & $\mathbf{p}$ \\
\hline Disturbe & $28(23.9)$ & $19(22.1)$ & $9(29.0)$ & \\
\hline Gestationnal age & $34.5 \pm 2.5$ & $35.0 \pm 2.3$ & $33.1 \pm 2.6$ & $<0.001$ \\
\hline $28-36 \mathrm{AW}$ & $89(76.1)$ & $61(70.9)$ & $28(90.3)$ & \\
\hline$>36 \mathrm{AW}$ & $28(23.9)$ & $25(29.1)$ & $3(9.7)$ & \\
\hline Delivery route & & & & 0.113 \\
\hline Low & $17(14.5)$ & 15 (17.4) & $2(6.5)$ & \\
\hline Caesarean & $100(85.5)$ & $71(82.6)$ & $29(93.5)$ & \\
\hline APGAR $1^{\text {st }}$ minute & & & & 0.002 \\
\hline$<7$ & $44(37.6)$ & $25(29.1)$ & $19(61.3)$ & \\
\hline$\geq 7$ & $73(62.4)$ & $61(70.9)$ & $12(38.7)$ & \\
\hline APGAR $5^{\text {th }}$ minute & & & & 0.007 \\
\hline$<7$ & $31(26.5)$ & $17(19.8)$ & $14(45.2)$ & \\
\hline$\geq 7$ & $86(73.5)$ & $69(80.2)$ & $17(54.8)$ & \\
\hline APGAR $10^{\text {th }}$ minute & & & & 0.037 \\
\hline$<7$ & $11(9.4)$ & $5(5.8)$ & $6(19.4)$ & \\
\hline$\geq 7$ & $106(90.6)$ & $81(94.2)$ & $25(80.6)$ & \\
\hline Birth weight (g) & $1792.8 \pm 598.4$ & $1940.9 \pm 540.7$ & $1381.5 \pm 564.6$ & $<0.001$ \\
\hline Low & $101(86.3)$ & $73(84.9)$ & $28(90.3)$ & \\
\hline Normal & $16(13.7)$ & $13(15.1)$ & $3(9.7)$ & \\
\hline Heigth $\mathrm{cm}$ & $42.4 \pm 4.0$ & $43.4 \pm 3.5$ & $39.6 \pm 4.2$ & 0.000 \\
\hline Cranial perimeter $(\mathrm{cm})$ & $30.4 \pm 2.7$ & $30.9 \pm 2.6$ & $28.8 \pm 2.3$ & 0.000 \\
\hline
\end{tabular}

Table 3. Predictors of short-term infant mortality.

\begin{tabular}{|c|c|c|c|c|c|c|c|}
\hline Factor & person-day & $\mathbf{n}$ & Incidence of death/100 P-D & RR $(95 \%$ CI $)$ & p & Ajusted RR $(95 \% \mathrm{CI})$ & $\mathbf{p}$ \\
\hline \multicolumn{8}{|c|}{ Gestationnal age AW } \\
\hline$\geq 37$ & 84 & 28 & 6.6 & 1 & & 1 & \\
\hline $28-36$ & 6 & 3 & 10.0 & $3.18(1.97-10.47)$ & 0.016 & $2.71(1.82-8.99)$ & 0.010 \\
\hline \multicolumn{8}{|c|}{ APGAR $1^{\text {st }}$ minute } \\
\hline$\geq 7$ & 10 & 12 & 2.8 & 1 & & 1 & \\
\hline$<7$ & 51 & 19 & 8.9 & $3.21(1.55-6.63)$ & 0.002 & $2.2(1.88-5.54)$ & 0.008 \\
\hline \multicolumn{8}{|c|}{ APGAR $5^{\text {th }}$ minute } \\
\hline$\geq 7$ & 17 & 17 & 3.3 & 1 & & 1 & \\
\hline$<7$ & 26 & 14 & 6.2 & $3.15(1.55-6.42)$ & 0.002 & $3.33(1.49-6.60)$ & 0.0005 \\
\hline \multicolumn{8}{|c|}{ APGAR $10^{\text {th }}$ minute } \\
\hline$>7$ & 52 & 25 & 6.9 & 1 & & 1 & \\
\hline$<7$ & 26 & 6 & 14.4 & $3.83(1.13-6.11)$ & 0.004 & $3.37(1.54-5.60)$ & 0.004 \\
\hline \multicolumn{8}{|c|}{ Overweight-obesity of monther } \\
\hline No & 18 & 14 & 4.3 & 1 & & 1 & \\
\hline Yes & 52 & 17 & 10.2 & $2.17(1.07-4.40)$ & 0.032 & $1.90(1.18-3.94)$ & 0.038 \\
\hline
\end{tabular}

Table 2 summarizes the general characteristics of the newborns according to the vital outcome and shows that the children of gestational age between 28-36 weeks of amenorrhea $(\mathrm{p}<0.001)$, APGAR $<7 \quad(\mathrm{p}=0.007)$, low birth weight $(\mathrm{p}<0.001)$ more deceased.

Short-term Survival Study of Newborns

Overall survival

The probability of survival of the children was $87.2 \%$ on the second day, 75.2 on the 5 th day, $73.5 \%$ on the tenth day, 73.5 on the thirtieth day. The median survival time was 12 days (IEQ: 10-15) (Figure 2).

The median survival at 30 days of follow-up is 3 days for children of gestational age under 37 weeks of gestation and 18 days for those over 37 weeks of amenorrhea. Indicating better survival of children of gestational age $\geq 37$ weeks of amenorrhea compared to those less than 37 weeks of amenorrhea with a statistically significant difference $(\mathrm{p}=0.039)$ (Figure 3$)$.

Survival is better in children with APGAR $\geq 7$, a median follow-up duration of 16 days, compared with 2 days for those with APGAR less than 7 with a statistically significant difference $(\mathrm{p}=0.001)$ (Figure 4).

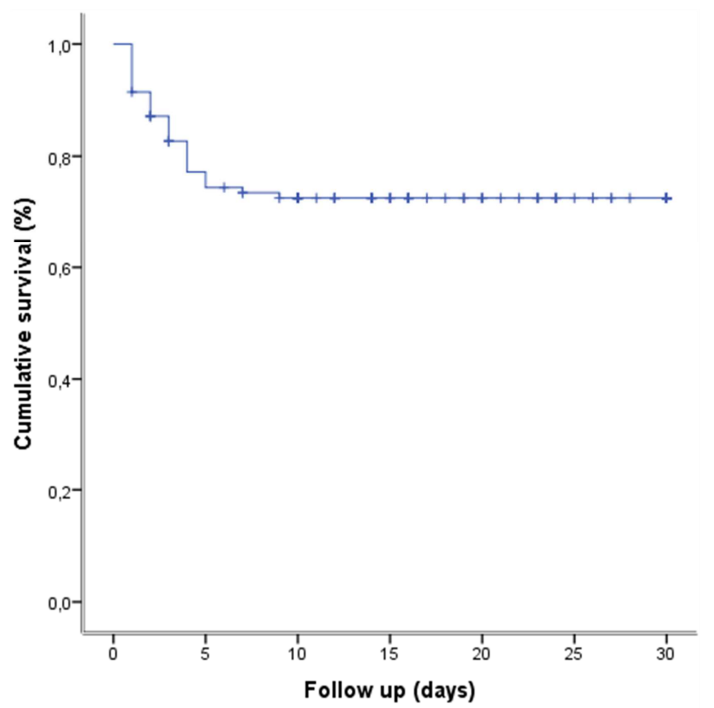

Figure 2. Probability of survival of children to days of follow-up in neonatology. 


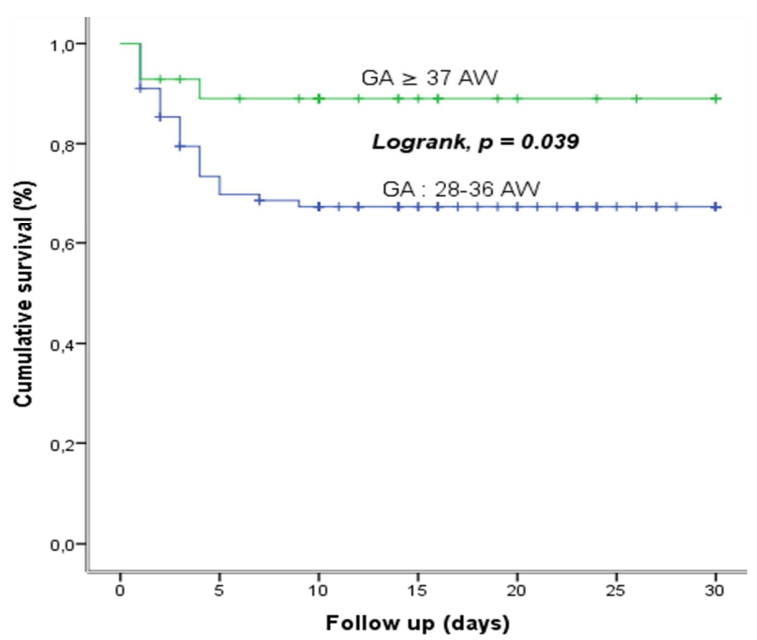

Figure 3. Child survival by gestational age at follow-up.

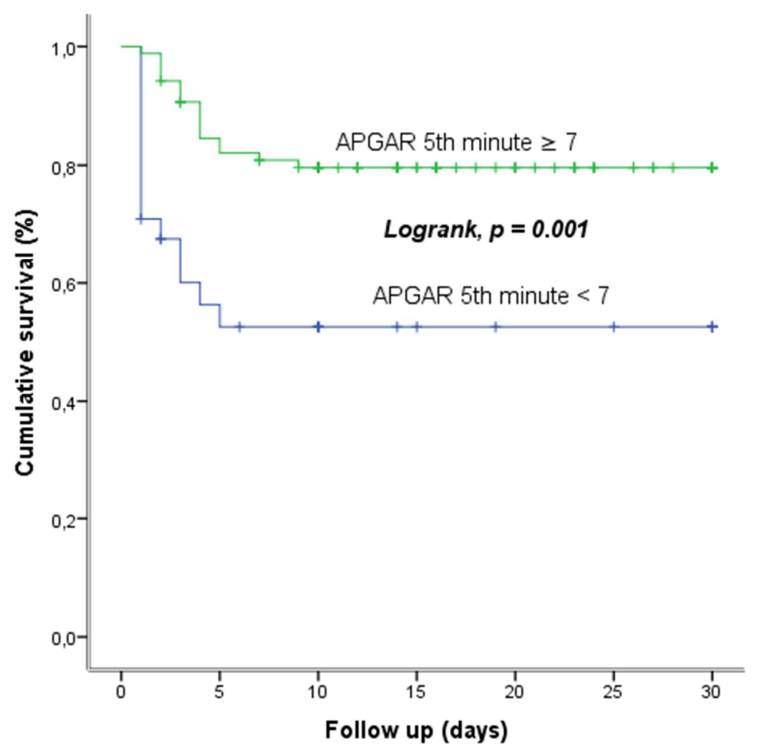

Figure 4. Child survival according to APGAR at birth.

According to Table 3, gestational age between 28-36 weeks of amenorrhea conferred a risk of death to children of 3 times, against to APGAR $<7$ at the 1 st, 5 th and 10 th which conferred a risk of 2, respectively, 3 and 3 times. The overweight-obese mothers had a risk doubled of causing the death of newborns.

\section{Discussion}

Preeclampsia is the expression of a hypo perfusion of the placenta (insufficient nutrition and oxygenation) which sees its own circulation deteriorate, resulting in ischemic placental lesions with fetal repercussions. The present study, involving 117 newborns having completed neonatal days, aimed to study the survival and predictors of mortality in these children during hospitalization.

The neonatal mortality rate in children born to preeclampsia mothers referred to neonatal care was $26.5 \%$. This rate is higher than that found by Monebenimp et al at the Yaoundé University Hospital in 2005, which was 3.58\% [9]; and close to that of Tietche et al who had found a rate of $20.48 \%$ in eutrophic newborns with HYC in 1998 [10]. This frequency is consistent with the findings made by the WHO according to which neonatal mortality rates are higher in developing countries [11]. This could be explained by the poverty and ignorance encountered in these countries, limiting access to care for mothers with preeclampsia and ignorance of the consequences of preeclampsia on the newborn by mothers.

The proportion of deaths was higher in neonates with gestational age $<37$ WA than in those with gestational age $\geq 37$ WA with a 3 -fold risk $(\mathrm{p}<0.05)$. Gestational age appears to be a good predictor of neonatal mortality in our study. This is in agreement with the results of several authors [12-14]. Lawn estimates that $28 \%$ of all neonatal deaths are due to preterm birth [15]. On the other hand, for Onwuanaku, although gestational age is not significantly related to neonatal mortality, he reports that the latter tends to occur more at gestational age below 37 weeks [16]. In our environment, as in most developing countries which are characterized by the impoverishment and underequipment of health structures, the rearing of premature babies poses serious problems and preterm birth is grafted with a high rate of neonatal death. The high case fatality rate linked to preterm birth found in our study could be explained by the fact that from birth to admission to our service through transfer, the premature baby does not benefit from any continuous care as he does. merit knowing that it has physiological immaturity of all organs (pulmonary immaturity, low carbohydrate reserves, immaturity of thermoregulation, immunological immaturity, neurological immaturity).

As for neonatal depression (Apgar score <7) was significantly associated with mortality in our study and in previous studies [17-19]. The need for neonatal intensive care which was noted considerably in the group of children with depression could be attributed to the high rates of intrapartal complications such as prolonged labor, obstructed labor which occurred more among the factors of the depression score. APGAR. Finally, we found that perinatal death was 3 times higher in children with APGAR $<7$ than in those with APGAR $\geq 7$; this would be secondarily due to the acute fetal distress and the poor Apgar score.

In the mother, the overweight-obesity of the mother had influenced neonatal mortality, this overweight-obesity of the mothers could be explained by the fact that the majority of mothers had an occupation. Overweight-obesity is often correlated with occupation; That is, a hardworking woman has a certain level of fat. This is how it has been shown in several studies conducted around the world that a working woman (and therefore one who has an occupation) is subject to a certain number of occupational risks: stress, intense physical work with the risk of sedentary lifestyle. which are the basis of obesity known to be a factor in the onset of low weight in general and in premature birth [20-22]. Knowing the impact of prematurity on mortality, obesity could indirectly intervene in newborn mortality. 


\section{Conclusion}

Pre-eclampsia is a pregnancy pathology with fairly high mortality for both the mother and the fetus. The most notable fetal complications it causes such as intrauterine growth retardation, prematurity, APGAR depression and fetal hypotrophy. These anomalies have their own significant impact on neonatal mortality, hence the need for preventive management through screening and early management of high-risk pregnancies.

\section{Author's Contributions}

RVV and ANN designed and analyzed the statistical data for the study. MTC, VND, TVA, MNB, and MFS contributed to the data collection. RRT, MMJM, ME and LMB supervised the study. All authors have read and approved the final and revised version of the manuscript.

\section{Conflict of Interest}

The authors declare that they have no competing interests.

\section{Acknowledgements}

We thank all who participated in the study.

\section{References}

[1] Zupan J. Perinatal Mortality in Developing Countries. N Eng J Med. 2005; 352 (20): 2047-2048.

[2] Bezzaoucha A, El Kebboub A, Aliche A. Évolution de la mortalité néonatale au CHU de Blida (Algérie) de 1999 à 2006. Bull Soc Pathol Exot. 2010; 103 (1): 29-36.

[3] Azoumah KD, Balaka B, Aboubakari AS, Matey K, Yolou A, Agbere AD. Morbidité et mortalité néonatales au CHU Kara (Togo). Med Afr Noire. 2010; 55 (2): 109-112.

[4] Bobossi-Serengbe G, Sana Deyamissi TS, Diemer HC, Gaudueille A, Gresenguet G, Mandaba JL, Siopathis RM. Morbidité et mortalité néonatales au Complexe pédiatrique de Bangui (Centrafrique). Med Afr Noire. 2004; 51 (3): 159-163.

[5] Vangu VR, Rahma RT, Mbuyi MJM, Mokondjimobe E, Mambueni TC, Vangu ND, Tsimba VA, Makoso NB, Mbungu FS, Nkodila NA, Longo-MB. Factors Associated with the Progression of Preeclampsia at Kinshasa University Clinics in Democratic Republic of Congo. European Journal of Preventive Medicine. 2020; 8 (5): 66-71.

[6] Verónica RM, Gallo LL, Medina DR, De la Torre MG, Mancilla J-L, Amezcua MM et al. Safe neonatal transport in the state of jalisco: impact of the STABLE program on morbidity and mortality. Bol Med Hosp infantile Mex. 2011; 68 (1): $31-35$

[7] Ancel PY, du Mazaubrun C, Bréart G. Grossesses multiples, lieu de naissance et mortalité des grands prématurés: premiers résultats d'EPIPAGE Ile de France. J Gynecol Obstet Biol Reprod. 2001; 30 (Suppl 1): 48-50.
[8] Monebenimp F, Tchio R, Nana AD. Morbidité et mortalité des naissances intra-hospitalières $\mathrm{du}$ centre hospitalier Universitaire de Yaoundé, Cameroun. Clinics in Mother and Child Health. 2005; Vol 2 (2): 355-358.

[9] Monebenimp F, Tchiro R, Nana AD. Morbidité et mortalité des naissances intra-hospitalières du Centre Hospitalier Universitaire de Yaoundé, Cameroun. Clin Mother Child Heath 2005; 2: 355-8.

[10] Tietche F, Kago I, Njimoke A, Mbonda E, Koki NP, Tetanye E. Mortalité hospitalière des nouveau-nés eutrophiques à terme à Yaoundé (Cameroun): Aspects étiologiques. Méd Afr Noire 1998; 45: 193-5.

[11] Fonds des Nations Unies pour l'Enfance (UNICEF). La situation des enfants dans le monde 2012-Les enfants dans un monde urbain. New York (NY): UNICEF; 2012.

[12] Hoan TP, Bao TV, Phong DN, Huong NT, Manirankunda L, Boelaert M. Mortalité néonatale précoce à l'Hôpital de gynécologie-obstétrique de Hanoï, Vietnam. Bull Soc Pathol Exot. 2000; 93 (1): 62-65.

[13] Kouéta F, Yé D, Dao L, Néboua D, Sawadogo A. Morbidité et mortalité néonatales de 2002 à 2006 au CHU pédiatrique Charles de Gaulle de Ouagadougou (Burkina Faso). Cahiers Santé. 2007; 17 (4): 187-191.

[14] Nagalo K, Dao F, Tall FH, Yé D. Morbidité et mortalité des nouveau-nés hospitalisés sur 10 années à la Clinique El FatehSuka (Ouagadougou, Burkina Faso). Pan African Medical Journal. 2013; 14: 153.

[15] Lawn JE, Cousens S, Zupan J. 4 millions neonatal deaths: When? Where? Why? Lancet. 2005; 365 (9462): 891-900.

[16] Onwuanaku CA, Okolo SN, Ige KO, Okpe SE and Toma BO. The effects of birth weight and gender on neonatal mortality in north central Nigeria. BMC Research Notes. 2011; 4: 562.

[17] Okunade KS, Okunola H, Oyeneyin L, Habeeb-Adeyemi FN. Cross-sectional study on the obstetric performance of primigravidae in a teaching hospital in Lagos, Nigeria. Niger Med J. 2016; 57 (5): 303-6.

[18] Ziadeh S, Yahaya A. Pregnancy outcome at age 40 and older. Arch Gynecol Obstet. 2001; 265 (1): 30-3.

[19] Hashim N, Naqvi S, Khanam M, Jafry HF. Primiparity as an intrapartum obstetric risk factor. J Pak Med Assoc. 2012; 62 (7): 694-8.

[20] Dole N, Savitz DA, Hertz-Picciotto I, Siega-Riz AM, McMahon MJ, Buekens P. Maternal Stress and Preterm Birth. Oxford Journals Medicine American Journal of Epidemiology. 2002; 157 (1): 14-24.

[21] Vendittelli F, Lachcar P. Menace d'accouchement prématuré, stress, soutien psychosocial et psychothérapie: revue de la littérature. Gynécologie Obstétrique \& Fertilité. 2002; 30 (6): 503-513.

[22] Epiney M, Boulvain M, Irion O. Facteurs de risque psychosociaux et accouchement avant terme. Rev Med Suisse. 2011; 7 (314): 2066-2069. 